\title{
The Effect of Water Contents to Diesel Fuel-Water Emulsion Fuel Stability
}

\author{
Joko Suryadi, Sugeng Winardi, and Tantular Nurtono
}

\begin{abstract}
The declining world oil and gas reserves along with increasing gas emissions from fossil fuel consumption has received serious attention as an urgent problem worldwide. The alternative solution to the problem uses emulsified fuel which is expected to provide better combustion efficiency and will contribute to emission reductions, such as $\mathrm{NO}_{\mathrm{x}}$ and particulate matter (PM). The one of most important factor in emulsion fuel is its stability. In this work, the effect of water contents to stability of diesel-water emulsion fuels has been investigated. The stability of emulsion fuel related to coalescence and sedimentation formation. The diesel fuel-water emulsification process was carried out in a standard stirred tank consisting of a cylinder tank $(93 \mathrm{~mm}$ in diameter) and Rushton disk turbine $(40 \mathrm{~mm}$ in diameter). Materials used consist of diesel oil (Pertamina DEX), demineralized water, surfactants (Lecithin, Triton X-100 and Tween 80). The surfactant used is a mixture of Lecithin - Triton X-100 (76.6\%: $23.4 \%)$ and Lecithin - Tween $80(45.5 \%: 54.5 \%)$ at $1 \%$ total volume of emulsion. The impeller set in constant speed at $1900 \mathrm{rpm}$. To reduce emulsification energy consumption, water is added gradually into the tank at $2 \mathrm{~mL} / \mathrm{min}$ of flowrate. Water content varies at $5 \%, 10 \%, 20 \%$, and $40 \%$ by total volume of emulsion. Physical properties of emulsion fuel such as viscosity and density at room temperature were investigated periodically. The characterization of emulsion fuel stability was measured by slope value of absorbance ratio at wavelength $450 \mathrm{~nm}$ and 850 nm. Sediment formation was periodically by visual observation as emulsion phase percentage. Emulsion droplet size was measured by Dynamic Light Scattering (DLS) method. Physical properties of emulsions such as density and viscosity tend to constant value in order of time. Emulsion fuel with $5 \%$ water content has the largest volume of emulsion phase in the rest of time, $83 \%$ for L-T emulsion fuel and $95 \%$ for L-Tx. The lowest slope value shown by $5 \%$ emulsion fuel water content, $8.657 \times 10^{-5}$ for $5 \%$ L-T emulsion fuel and $-2,084 \times 10^{-4}$ for $5 \%$ L-Tx emulsion fuel. Droplet size measurement of emulsion shown that different amount of added water caused the different droplet size of emulsion.
\end{abstract}

\section{Keywords—Emulsion Fuel, Mixed Surfactants, Low Energy Emulsification.}

\section{INTRODUCTION}

$\mathrm{D}$ iesel fuel still used in industry and transportation sector because of its high efficiency in diesel engine. However, it has the negative impact of using the diesel fuel especially in produced the large amount of emission. Particulate material $(\mathrm{PM})$ and nitrogen oxide $\left(\mathrm{NO}_{\mathrm{x}}\right)$ are the characteristic kinds of emission that produced by diesel engine [1][2]. Several methods are implemented to reduce emission such as instrumental modification. $\mathrm{NO}_{\mathrm{x}}$ Absorber Catalyst (NAC) and Selective Catalytic Reduction (SCR) to reduces $\mathrm{NO}_{\mathrm{x}}$ emission and Diesel Particulate Filters (DPFs) to reduce the PM emission [3]. Other method that implemented to reduce the both emissions is introducing the water to the diesel engine. However, the instrumental methods are costly, engine modification, difficult to reduce emissions simultaneously, and tend to form corrosion.

Emulsion fuel was introduced to diesel engine that can reduce the emission without diesel engine modification [4]. Diesel fuel-water emulsion is an emulsion system that water acts as dispersed phase and diesel fuel as continuous phase. Diesel-water emulsion may reduce $\mathrm{PM}$ and $\mathrm{NO}_{\mathrm{x}}$ because of micro explosion phenomena and dispersed phase vaporization mechanism.

Stability of diesel fuel-water emulsion is the one of important factor that can be required as fuel. The ability of emulsion against sedimentation that caused by coalescence and flocculation in long period is a diesel fuel emulsion parameter stability. Several factors that causes stability emulsion such as kinds and concentration of surfactant, emulsification techniques, water contents, and time occurred in emulsification process.

Joko Suryadi, Sugeng Winardi, and Tantular Nurtono are with Department of Chemical Engineering, Institut Teknologi Sepuluh Nopember, Surabaya, 60111, Indonesia. E-mail: jokosuryadi2010@gmail.com.

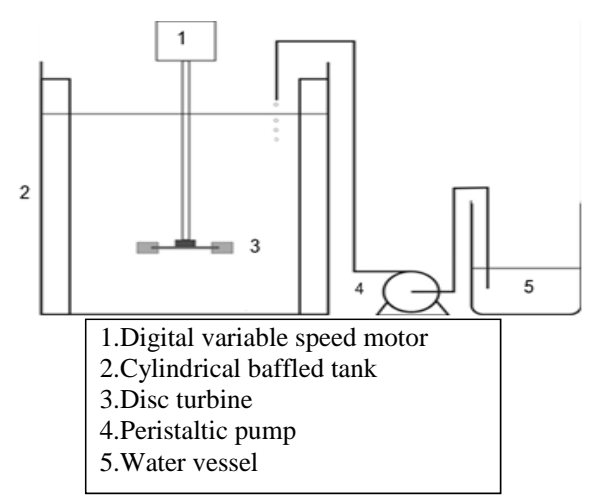

Figure 1. Experimental Setup of Low Energy Emulsification.

There are several researches that concerned in dieselwater emulsion fuel with various kinds of surfactants, methods, and water contents [4]. Almost surfactants used in diesel-water emulsion are sorbitan type compounds [5]. High energy emulsification is the common method to produce diesel-water emulsion. Two major of high-energy emulsification methods are high shear homogenizer and ultrasonication process. These methods are effective to produce the diesel fuel-water emulsion that good in stability [6], [7], and [8]. However, high-energy emulsification consumes large amount of energy. Alternatively, low energy emulsification can be implemented to produce the stable diesel fuel-water emulsion with good stability until 90 days according to the emulsion droplet size in various amount of water contents [9].

In this research, diesel fuel-water emulsion was produced with low energy emulsification method. Lecithin was used as natural based surfactant that mixed to Tween 80 and Triton X-100. The main objectives of this research are investigating effect of water contents in diesel fuel-water emulsion to the physical characteristic 


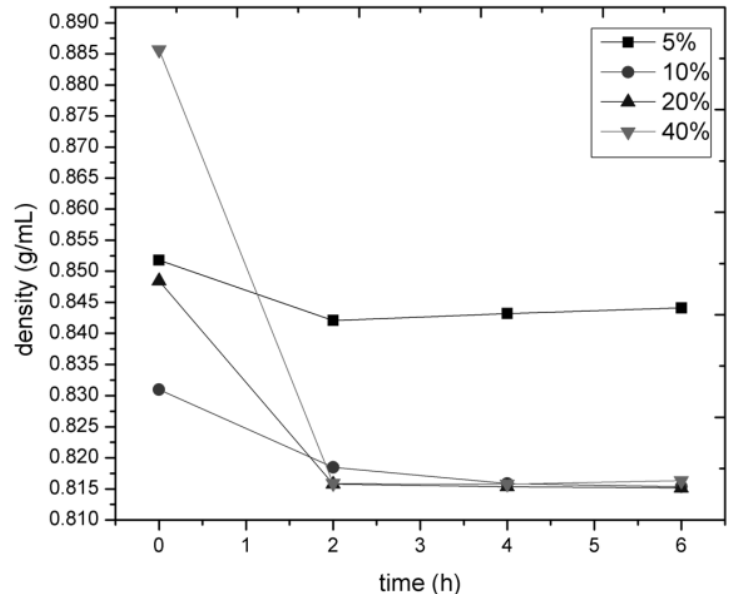

(a)

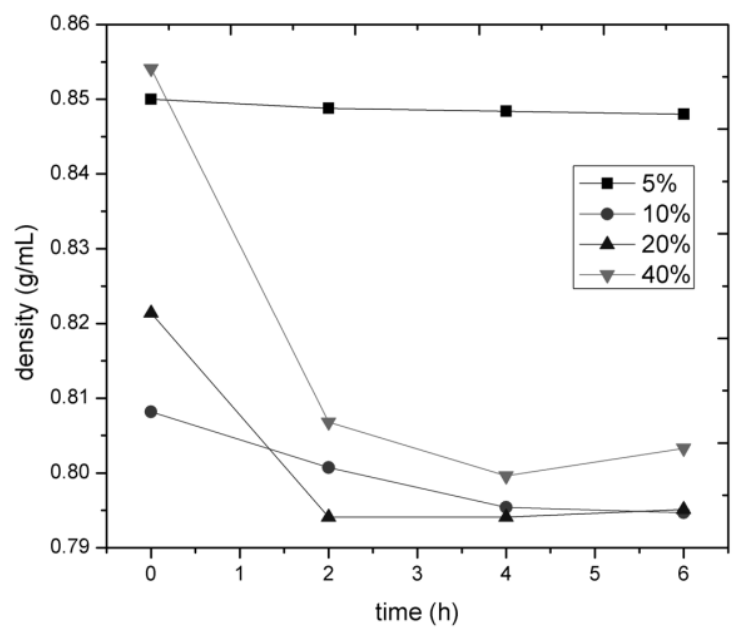

(b)

Figure 2. Emulsion diesel fuel density value as function of time at water contents variable: a. Emulsion with L-T surfactant; b. Emulsion with L-Tx surfactant.

and stability parameter. Hopefully, diesel fuel-water emulsion can become the diesel engine alternative fuel because of environmental aspect.

\section{METHOD}

\section{A. Materials}

Ultralow sulphur diesel fuel (Pertamina Dex) as the continuous diesel fuel phase. Demineralized water as dispersed phase, technical grade lecithin, Tween 80 (Merck), Triton X-100 (Merck) as surfactants and carboxymethyl cellulose (CMC) as lecithin-Tween 80 coemulsifier.

\section{B. Material Preparation}

There are two kinds of mixed surfactants used in this work. Mixture of lecithin and Tween 80 with composition $45.5 \%$ lecithin and $54.5 \%$ Tween 80 at mass ratio (L-T). The second type of mixed surfactant is mixture between lecithin and Triton X-100 with composition 76.6\% lecithin and $23.4 \%$ Triton X-100 at mass ratio (L-TX). CMC $0.5 \%$ was prepared in demineralized water as coemulsifier to L-T surfactant emulsion system.

\section{Emulsification processing}

Emulsification processing occurred in low energy emulsification that dispersed phase was added to the continuous phase in specific flowrates constantly. Sample in $93 \mathrm{~mm}$ of diameter baffled cylinder reactor was mixed

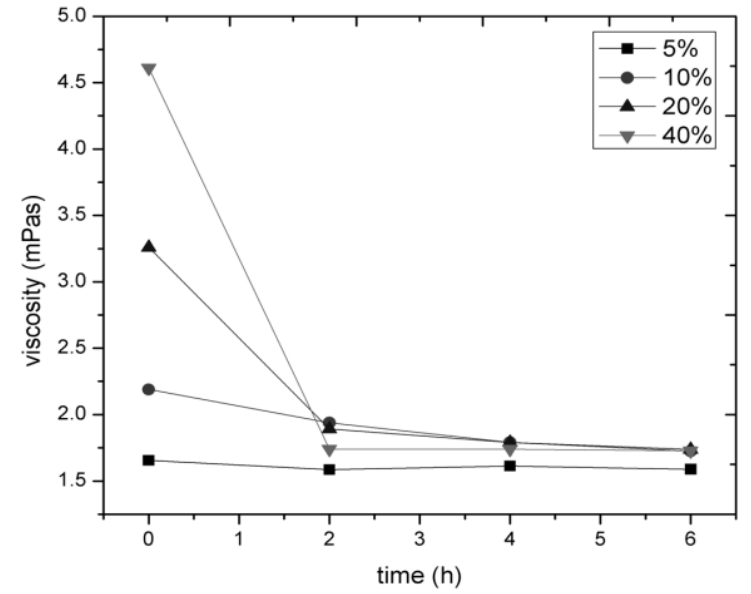

(a)

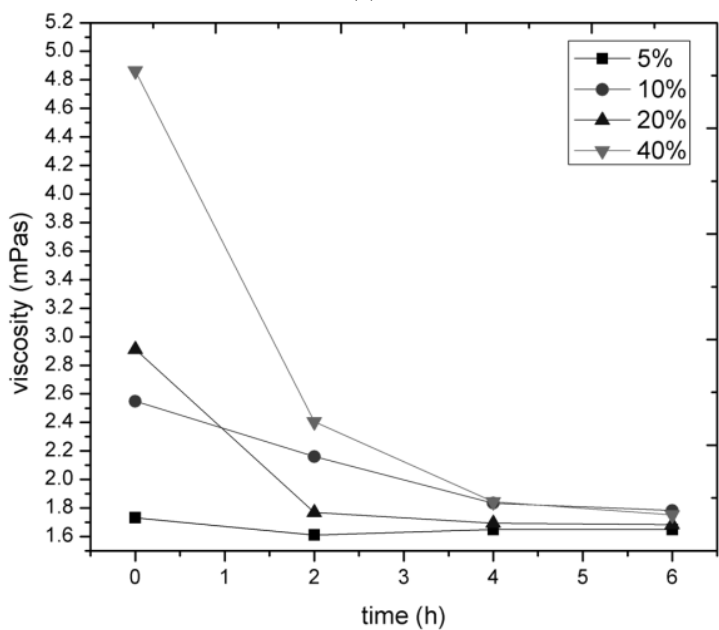

(b)

Figure 3. Emulsion diesel fuel viscosity value as function of time at water contents variable: a. Emulsion with L-T surfactant; $b$. Emulsion with L-Tx surfactant

with $40 \mathrm{~mm}$ of diameter Rushton's disk turbine impeller at $1900 \mathrm{rpm}$. Concentration of surfactant was set on $1 \%$ of total volume. Water contents were varied at $5 \%, 10 \%$, $20 \%$, and $40 \%$ of total volume at $2 \mathrm{~mL} / \mathrm{min}$ to the continuous phase. Emulsification time depended on water that all finally transferred into emulsification tank and extra 20 minutes were added after that. The total volume of sample (dispersed water, surfactant, and continuous phase) was set at $600 \mathrm{~mL}$ volume.

\section{Characterizations}

Physical properties of emulsion fuel such as viscosity and density were measured with Ostwald viscometer and pycnometer. Sediment formation in sample observed visually with transparent scaled cylinder tube. The emulsion phase that remain in sample expressed in height percentage of sample total height as shows in Eq. 1. Symbols A and B are expressing the height of emulsion phase (the middle phase in cylinder tube) and height of total volume respectively.

$$
\% E=\frac{A}{B} \times 100 \%
$$

Physical properties and sediment formation investigated periodically until six hours after emulsification process. The stability parameter of diesel fuel emulsion analyzed with turbidity ratio method [10]. Emulsion sample by L-T and L-Tx surfactant was diluted $25 \mathrm{x}$ and $250 \mathrm{x}$ in paraffin oil respectively. Turbidity ratio measured by value of ratio 


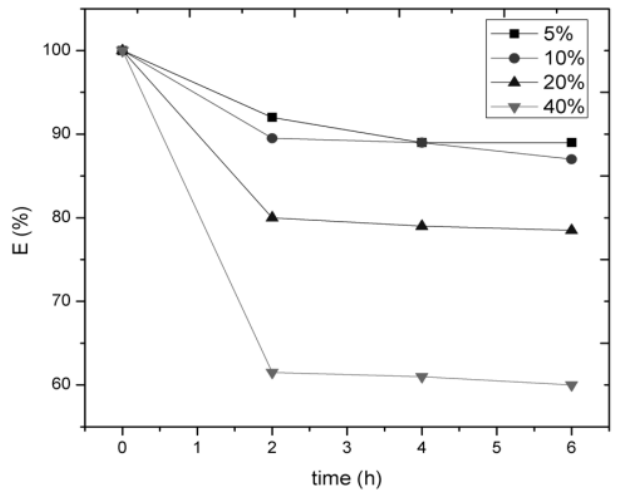

(a)

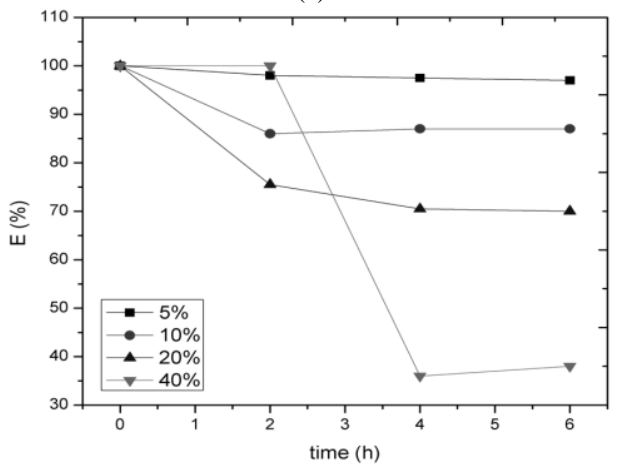

(b)

Figure 4. Emulsion diesel fuel phase as function of time at water content variable: a. Emulsion with L-T surfactant; b. Emulsion with L-Tx surfactant.

(R) between absorbance at $850 \mathrm{~nm}\left(\mathrm{~A}_{850}\right)$ and $450 \mathrm{~nm}$ (A450) with Spectrophotometer UV-Vis (Genesys) expresses in Equation 2. Turbidity ratio value was measured continuously until 60 minutes with 10 minutes' interval.

$$
R={ }^{A_{850}} / A_{450}
$$

Droplet size of emulsion determined by Dynamic Light Scattering (Malvern Zetasizer Nano) at smallest and largest of water content value to review the relationship between droplet size and water content. The similar sample preparation was set in absorbance and droplet size measurement.

\section{RESULTS AND DISCUSSION}

A. Physical properties characteristics and sediment formation observation of emulsion fuel.

Density and viscosity value as physical properties of emulsion fuel was observed periodically. It purposes to review the consistency of emulsion fuel physical properties by time.

The highest value of density and most constant emulsion fuel was shown at $5 \%$ water content on both of emulsion system. The emulsion fuel with $5 \%$ water can formed the best interaction between surfactant, water as dispersed phase, and diesel fuel as continuous phase. Density tended to shifting by time because of surfactant system disability to interact with water at larger amount. Water will be separated gradually, and oil phase remains.

Viscosity values for 6 hours at two kinds of emulsion system tended to decreasing. This phenomenon was caused by separation of emulsion system to each component. The faster viscosity value was changing closely related to emulsion stability. Emulsion fuel with

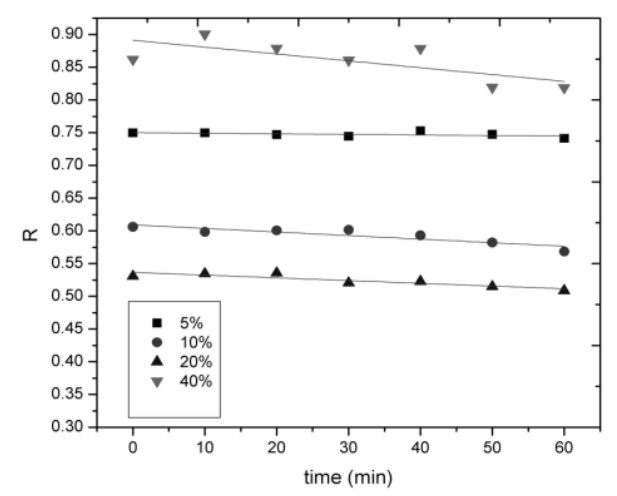

(a)

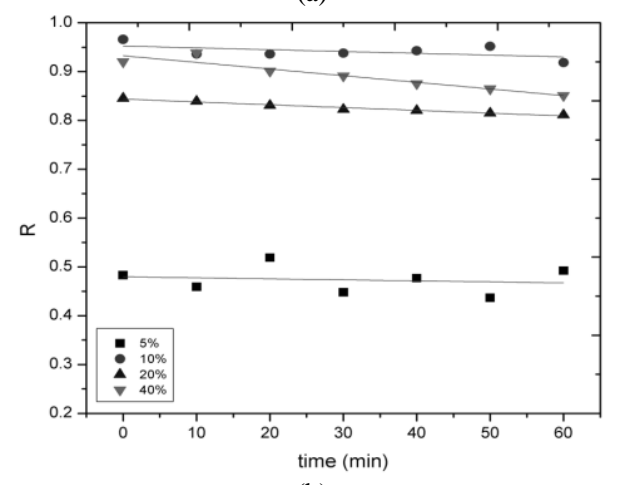

(b)

Figure 5. Absorbance ratio as function of time at water content variable: a. Emulsion with L-T surfactant; b. Emulsion with L-Tx surfactant.

$5 \%$ water content shown the most constant of viscosity value because the surfactant system able to maintain emulsion fuel stability at $5 \%$ water content.

Sediment formation in diesel fuel emulsion can describe its stability. By time, emulsion form the aggregate. The bigger aggregate causes coalescence phenomenon and form sediment at final. The sediment will collect at bottom side of emulsion container because of gravity. The faster emulsion form sediment shows the emulsion is more unstable. The relationship of emulsion phase remains depended to time is described in Fig. 4. Emulsion diesel fuel with $5 \%$ water content had the highest volume of emulsion phase and most stable due to amount of emulsion phase by time. At the rest of observation, L-T emulsion fuel had $83 \%$ and L-Tx emulsion fuel had $95 \%$ emulsion phase. Increasing of water content causes higher and faster of forming sediment in emulsion diesel fuel.

\section{B. Effect of water content to emulsion stability.}

Emulsion stability observation by turbidimetry method was occurred in 60 minutes with measured at 10 minutes interval. Trends of absorbance value plotted in linear equation. The most stable emulsion fuel has the linear equation with slope closely to zero. It means there is no change in the emulsion system at particle scope.

Fig. 5 shows the trend of absorbance ratio depending of time. At specific wavelength, particles in emulsion was able to scatter the lights depend on the particle size. Small particle size tended to scatter the short wavenumber and vice versa. The turbidity ratio $(\mathrm{R})$ describes the distribution of particle size, where particle size distribution more heterogenic at $\mathrm{R}$ value closely to 1 .

Decreasing of absorbance value to time caused by particles in emulsion form the bigger aggregate and settled at bottom. Small particles were remained in emulsion 
TABLE 1.

SLOPE VALUE OF EMULSION FUEL BY TURBIDITY RATIO MEASUREMENT

\begin{tabular}{ccc}
\multicolumn{3}{c}{ MEASUREMENT } \\
\hline \hline $\begin{array}{c}\text { Water } \\
\text { content [\%] }\end{array}$ & L-T & Slope value \\
\hline 5 & $-8.657 \times 10^{-5}$ & $-2.084 \times 10^{-4}$ \\
10 & $-5.465 \times 10^{-4}$ & $-3.704 \times 10^{-4}$ \\
20 & $-4.188 \times 10^{-4}$ & $-5.763 \times 10^{-4}$ \\
40 & $-1.050 \times 10^{-2}$ & $-1.360 \times 10^{-2}$ \\
\hline
\end{tabular}

TABLE 2.

DROPLET SIZE OF EMULSION DIESEL FUEL - WATER

\begin{tabular}{ccc}
\hline \hline Surfactant type & Water content [\%] & $\begin{array}{c}\text { Droplet size } \\
\text { [nm] }\end{array}$ \\
\hline \multirow{2}{*}{$\mathrm{L}-\mathrm{T}$} & 5 & 3,782 \\
& 40 & 4,669 \\
$\mathrm{~L}-\mathrm{Tx}$ & 5 & 2,662 \\
& 40 & 9,239 \\
\hline \hline
\end{tabular}

phase and causing the $\mathrm{R}$ value smaller because the bigger aggregate has settled and undetectable at same point in UV-Vis instrument. Both of L-T and L-Tx emulsion fuel, at $5 \%$ water content had the lowest slope value and at 40 $\%$ shows the highest. Minus (-) value of slopes describes the trend of decreasing. From the slope value, it can conclude that emulsion with $5 \%$ is the most stable. The slope value of emulsion fuel expresses in Table 1.

The aim of droplet size measurement was to review the relationship between droplet size and water content. The measurement only occurred at $5 \%$ and $40 \%$ in both of emulsions (L-T and L-Tx surfactant) because these samples represent the interval of water content effect. Result of measurement expresses in Table 2. Droplet size of emulsions increasing due to water content in emulsion fuel. Larger droplet size of emulsions causes emulsion stability decreasing because easier to coalescence and form the sediment.

\section{CONCLUSION}

Physical properties of emulsion diesel-fuel such as viscosity and density with a water content of $5 \%$ had a tendency not to change with time. Emulsion phase of $5 \%$ water content has the largest volume and not to change for 6 hours observation. According to the slope value of turbidity method, emulsion diesel fuel with $5 \%$ water content is the most stable. The droplet size of diesel fuel directly proportional with water content and inversely with emulsion stability.

\section{REFERENCES}

[1] A. Resitoglu, K. Altinisik, and A. Keskin, "The pollutant emissions from diesel engine vehicles and exhaust after treatment systems," Clean Technol. Environ. Policy, vol. 17, pp. 15-27, 2015.

[2] K. Hassanuddin et al., "Stability studies of water-in-diesel emulsion," Appl. Mech. Mater., vol. 663, pp. 54-57, 2015.

[3] M. Ithnin, H. Noge, H. Kadis, and W. Jazair, "An overview of utilizing water-in-diesel emulsion fuel in diesel engine and its potential research study," J. Energy Inst., vol. 87, pp. 1-16, 2014.

[4] Y. Khan, A. Karim, Y. Hagos, A. Aziz, and M. Tan, "Current trends in water-in-diesel emulsions as a fuel," Sci. World J., pp. $1-15,2014$.

[5] S. Vellaiyan and S. Amirthagadeswaran, "The role of water-indiesel emulsion and its additives on engine performance and emission levels: a retrospective review," Alexandria Eng. J., vol. 55, pp. 2463-2472, 2016

[6] M. Al-Sabagh, M. M. Emara, N. El Din, and R. Aly, "Formation of water-in-diesel oil nano-emulsions using high energy method and studying some of their surface active properties," Egypt. J. Pet., vol. 20, pp. 17-23, 2011.

[7] N. El-Din, H. El-Hamouly, M. Mohammed, M. R. Mishrif, and A. M. Ragab, "Water-in-diesel fuel nanoemulsions: preparation, stability and physical properties," Egypt. J. Pet., vol. 22, pp. 575 581, 2013.

[8] S. Bidita, R. Suraya, A. Shazed, A. Mohd-Salleh, and A. Idris, "Preparation, characterization, and engine performance of water in diesel nanoemulsions," J. Energy Inst., vol. 89, pp. 1-12, 2016.

[9] N. El-Din, I. Osman, M. Rashad, R. Mishrif, and A. El-Sharaky, "Physicochemical and rheological characterization of diesel fuel nanoemulsions at different water and surfactant contents," $\mathrm{J}$. Mol. Liq., vol. 231, pp. 440-450, 2017.

[10] G. Song, H. Cho, Y. Kim, and D. Kim, "Novel evaluation method for the water-in-oil (W/O) emulsion stability by turbidity ratio measurements," Korean J. Chem. Eng., vol. 19, pp. 425-430, 2002 . 